\title{
'Images, Reflections, Mirrors': Student Perspectives on the Financial Crisis and Challenges for Development
}

\author{
Lars Otto Naess*
}

\begin{abstract}
This site explored student perspectives on development in view of the current financial crisis. The site worked with the $2009 / 10$ cohort of IDS students, focusing on their motivations for entering the development sector, their experience with the financial crisis, as well as their views on potential spaces for change. The site brought out the paradox of, on the one hand, the significant impacts of the financial crisis, and on the other, the apparent lack of change in the way development is carried out. Using a policy processes perspective, this article suggests that the slow pace of change may be explained by a wide variety of values among actors, and by the interest of actors in working within, instead of challenging, existing institutional structures. Opportunities for policy change may arise with new actors, but this also raises questions around participation of marginalised voices.
\end{abstract}

\section{Introduction}

The financial crisis has been seen as a key moment for rethinking or reimagining development policy and practice (Haddad et al., this IDS Bulletin). This site aimed to shed light on the financial crisis from IDS students' perspectives, providing them with a space for reflection on its implications. A student perspective was chosen for several reasons. Students are representatives of the next generation of development practitioners, academics and policymakers. Further, IDS students played a prominent role in developing the so-called 'Brighton Woods' initiative, which helped stimulate the Reimagining Development initiative. And the diversity of students' backgrounds gives a good sounding board for discussions on the effects of the crisis and future challenges and opportunities. For the 2009/10 academic year, MA students at IDS represented 36 countries across five continents, the majority of which had prior practical development experience.

This article takes a policy process perspective on the development sector's exposure to the financial crisis. Policy processes are viewed as complex, non-linear and 'messy', driven by actors with diverse sets of interests who subscribe to particular narratives or framings of problems and their solutions (Keeley and Scoones 2003). Adapting the 'garbage can' model (Cohen et al. 1972), Kingdon (1995) shows how a crisis situation can provide a policy window bringing about rapid change when there is a convergence of interests or values, agendas and actors.

'Garbage can' illustrates that organisations tend to produce more solutions than there are problems, many of which are discarded to the 'garbage can', and that the occurrence of a new problem, such as, in this case, the financial crisis, tends to give a wide range of competing solutions.

We focused on three interrelated questions, broadly overlapping with the overall research questions of the Reimagining Development initiative: (1) What are students' motivations for working with development? (2) What are their experiences from working through the financial crisis, and what effects did they have on people's lives, values, relationships, and behaviour?

(3) What do they see as new emerging challenges, and the spaces for change?

\section{Methods and research process}

Data for this site were collected between May and July 2010 through a lunch seminar, a focus group discussion and a web-based survey. 
Overall, about 30 per cent of the 2009/10 IDS student cohort participated in at least one of the three activities under the site. ${ }^{1}$ The study was initially set up through the MA student group on climate change, a self-selected group of students with a particular interest in climate change and the challenges it poses to development. As the site developed, the focus of the site broadened, as it was felt that a wider perspective was needed in order to capture the range of motivations, changes and outcomes of the financial crisis.

The lunch seminar was set up to capture students' broad motivations for working with development and experiences of the financial crisis, and helped frame the questions for the second focus group discussion as well as the web survey. Seven students were invited to share their personal experiences with the crisis, including how it had affected their work or their friends or colleagues, and how it had shaped their understanding of key development challenges. Care was taken to include a diverse range of students in terms of geographical origin, gender and areas of work and study. Building on the seminar, the focus group discussion allowed a more in-depth discussion about motivations, effects of the financial and other crises and new opportunities and challenges. While the latter was open to all students, the timing (outside term time) and the time commitment (two hours) meant that participants were invited individually based on their interest and previous contact with the site. The web-based survey was conducted subsequent to the group discussions, to triangulate and add to perspectives from the group discussions. The survey contained a mix of closed and open-ended questions, and focused on the same broad themes as the group discussions.

The data were analysed qualitatively, looking at response patterns and key themes that emerged with regard to the theory and research questions, and using quotes and examples from responses to illustrate these. Thus, the findings represent a selection of student perspectives, but for obvious reasons, cannot claim to present the full range of IDS student perspectives.

\section{Findings}

\subsection{Motivations and values}

Many emphasised that they entered development to make a positive difference to people's lives. Some said they had to overcome disapproval from families and peers for wanting to work with development, when there were other options that were better paid and earning more respect. For example, one student was asked: 'When you can have a more settled life back home, why worry about what's going on in Africa? That's for them to solve'. Perhaps unsurprisingly, the outside image of development for many was one of altruistic choice and sacrifice, which for some led to subsequent disappointment - some mentioned that experiences with practical development had sometimes made them uneasy. Before starting they had expected it to be better than other areas of work, but had found that in practice, it was not. Others were disappointed when hearing about fellow students or volunteers going into development for adventure, to travel the world or to build their GVs. But some also raised the issue of what we expect the development sector to be: 'we should be prepared that things don't work, even in development... there can be hypocrisy, bureaucracy... when we are trying to engage with something complex... it's too naive to think that there would be nothing wrong with practices in this sector'. Studying development made students more aware of the complexities and many facets of development, but also of the many challenges within the sector.

\subsection{Effects of the financial crisis: scope for learning?}

Many students had stories about the effects of the crisis before joining IDS. Some had experienced negative impacts of the crisis first hand, with budgets being cut and family and friends losing their jobs and countries going through painful adjustments. Otherwise, the effects of the financial crisis were mixed. For them personally, some see the crisis and the changes that followed as a risk to their careers, with fewer jobs available. Others see the need for development assistance as increasing rather than decreasing, and precisely because things have gone badly wrong, their skills will be needed more than ever before.

One student said the biggest effect he noticed was a value change; a change in people's mood and attitude to development, resulting in less solidarity towards developing countries and more concern with their own affairs. Another, who had worked part time in consultancy, saw how their opportunities had actually increased, as the government was deregulating and outsourcing the work they would normally do. More broadly, there was a sense that not much had really 
changed to the underlying structures. One student said she felt it a paradox that banks in India, which, due to being more regulated than other parts of the world, suffered little from the financial crisis, now found themselves under international pressure to deregulate.

At the same time, it was felt that while it was easy to blame the government or the World Bank for past development failures, it was different this time, with the rather amorphous international financial system as the culprit. This made it harder to pinpoint who caused the problem, in what was essentially a systemic failure. Herein was also a frustration of what was seen as a tendency of looking mostly at solutions at local and national levels, often letting the macrolevel power structures go unchallenged.

This was exemplified also in the way they saw themselves as privileged in being part of the development sector. People come from different backgrounds, but many are acutely aware of the ability to pursue their interest in development. Students' responses suggest a critical view on development and development actors (including IDS), but also a keen awareness that we are all part of it.

\subsection{Opportunities: spaces for change?}

While students felt that much was still operating as 'business as usual', almost all survey respondents felt that the crisis had opened new spaces for thinking differently about development, in academia as well as development practice. Opportunities for change were seen both in how the financial crisis presented a policy window that 'was impossible to ignore', and climate change as another factor that could leverage 'increasing and improving social dialogue' for marginalised groups.

But perhaps the clearest new space was the role of the emerging powers. Students pointed to the increasing competition from the new emerging actors on the development arena, in the form of India, China and the Middle East. As the crisis gave rise to a view that the Western model had failed, it made it easier for the new powers to enter. At the global level, they are changing the face of development. One widespread view appeared to be that as many of the traditional aid structures are still in place, they may become less relevant as other parts of the world is moving on. To some, the Western model had been exposed, to others a challenge to rethink. When Western countries are losing influence from cuts in funding, others are moving quickly in.

One student pointed out how the types of support given by the new powers were different from traditional ones, with more support to tangible structures and specific groups such as children, and less on structural issues such as gender. Views on emerging powers such as India, China and Middle East countries ranged from being interested in their pragmatic ways of thinking, to a concern that hard-won rights and institutions could be put at risk. But what is clear - which students amply pointed out - was that we need to look at these new powers with realistic eyes, as actors that are here to stay, and are gaining increasing power.

\section{Discussion}

Previous sections pointed to the financial crisis as 'too big to ignore' and having large impacts on people's lives, yet little seems to be happening to change development practice. Three areas of challenges - and possible opportunities - may be identified in order to help explain this apparent paradox.

\subsection{Images of the development sector}

First, responses show how students are grappling with changing national moods and reduced support for development aid, sometimes scepticism from their peers, as well as the cognitive dissonance between their expectations of the development sector and their experience of it. Studying development had made them more aware of the range of complexities of what development is, but still pointing to the tension between wanting to change an area they are increasingly - through work and study - also becoming part of. Kingdon (1995) shows how specialists in a policy area tend towards having the same set of underlying values, discouraging policies that fall outside the mainstream. Through case studies in Africa, Keeley and Scoones (2003) demonstrate how actor networks in environmental policy areas work together to promote certain policy pathways. Following the disillusionment with the traditional development sector (i.e. international aid agencies, NGOs and development research institutions), new actors, such as emerging economies, were by some seen as an opportunity for broadening the debate beyond the traditional development actors. 


\subsection{Reflections and learning}

Second, student views on more avenues for development work illustrate another challenge, namely the scope for learning from current development failures in view of the financial crisis. Open policy windows, such as the financial crisis has brought, do not automatically bring change, but need policy entrepreneurs to couple problems and solutions (Lipson 2007). Student responses suggest that while learning takes place at individual and local levels, they see little or no attention given to the broader structures that make societies vulnerable to shocks. The discussion around solutions to the financial crisis - including in teaching programmes at IDS and elsewhere - was seen as primarily geared towards working within current structures. A parallel can be seen in debates on adaptation to climate change, which commonly focuses on adaptation as improving current development practices, rather than examining the structures that cause vulnerability (Brown 2011).

\subsection{Mirrors: policy choices and challenges}

Third, as pointed out above, students' responses point to possible opportunities for change in new actors with new approaches and solutions.

However, according to the 'garbage can' model, any problem will have a surplus of solutions to it. The choice of policy option is not a matter of objective weighing of a range of options, but rather an outcome of political processes with a fluid and changing set of actors. Unlike other development problems, the number of actors involved in the financial crisis made it harder to identify exactly who caused the financial crisis,

\section{Notes}

* Many thanks to Nidhi Dhingra and Mohammed Nurul (Nur) Azam who, together with Dipanwita Das, tirelessly led this student site. Thanks to Heather Williams for helping to get the site off the ground, and supporting it all the way through; to Naomi Hossein and Lyla Mehta for support as site theme leaders and to the above, as well as Lawrence Haddad and Allister McGregor for useful comments which also suggests that solutions may vary widely from one context to another. More development actors give more spaces or outlets for discussing change, but also a broader range of values, and in turn wider range of views of problems and solutions to address vulnerabilities to financial (and other crises). The rise of China in Africa, for example, is widely documented, and was pointed out as an example of actors with new types of solutions that are increasingly challenging traditional actors and forcing them to rethink. While this was seen as an opportunity for reimagining development, it also raises important questions around how marginalised groups are considered. By default, less powerful actors will not be able to bring their preferred policy options to the decision-making arena, cementing established power structures and leading to closing of policy spaces.

\section{Conclusions}

Students' perspectives give a sense of the increasing complexity in the development sector and the challenges it brings in rethinking development in the context of financial and other crises. Findings suggest that changing values, interests of actors in working within existing institutional structures, and the entering of new actors, help explain why, despite the financial crisis as a window of opportunity, change is happening slowly. While opportunities for change exist in new actors entering, forcing a rethink among traditional development actors, questions remain around to what extent marginalised groups are heard in these processes.

on earlier drafts. And last, but certainly not least: a huge thanks to all the students who participated in the activities under this site.

1 This included about 15 in the lunch seminar (19 May 2010), six in the focus group discussion (1 July 2010) and 20 in the survey (4-13 July 2010). Accounting for those who participated in more than one activity, about 35 or just over 30 per cent of the total 2009/10 IDS MA student cohort (114) took part. 


\section{References}

Brown, K. (2011) 'Sustainable Adaptation: An Oxymoron?', Climate and Development 3: 21-31 Cohen, M.D.; March, J.G. and Olsen, J.P. (1972) 'A Garbage Can Model of Organizational Choice', Administrative Science Quarterly 17.1: $1-25$
Keeley, J. and Scoones, I. (2003) Understanding Environmental Policy Processes: Cases from Africa, London: Earthscan

Kingdon, J.W. (1995) Agendas, Alternatives, and Public Policies, 2nd edn., New York: Longman Lipson, M. (2007) 'A "Garbage Can Model” of UN Peacekeeping', Global Governance 13: 79-97 